\title{
Erratum: Personal medicine_-the new banking crisis
}

Christopher Thomas Scott, Timothy Caulfield, Emily Borgelt \& Judy Illes

Nat. Biotechnol. 30, 141-147 (2012); published online 8 February 2012; corrected after print 24 February 2012

In the version of the article originally published, the citation in Figure 1 was given as ref. 14; it should be ref. 2. In Table 1, CARTaGENE was misspelled, and the descriptions in column 3 of this repository, BioVu's and the International HapMap were incorrect: CARTaGENE should be described as "A repository of socio-demographic, health data and biological samples from 20,000 citizens of the province of Quebec in Canada"; BioVu's description should read "Repository of DNA samples and de-identified health information from the Vanderbilt University Medical Center's electronic system"; and the International HapMap description should read "International collaboration with the ultimate goal of developing a haplotype map of the human genome." In addition, the amount of the Havasupai settlement was incorrectly stated to be $\$ 700$ million. It should read \$700,000. Finally, the work of Simon et al. (ref. 8) on biobank consent models was incorrectly described. The text should read, "For example, a recent US focus group and survey study found a public that preferred a broad approach to consent over ones involving additional choices. But the preference was marginal, thus noting the lack of consensus on these issues. Indeed, as noted by the authors of the study: ' $54 \%$ of our survey and $42 \%$ of our focus group participants could be seen as preferring a control/choice-promoting model (e.g., categorical or study-specific consent) over a control/choice demoting model (e.g., broad consent) ${ }^{8}$.' The errors have been corrected in the HTML and PDF versions of the article.

\section{Erratum: Existing agbiotech traits continue global march}

\section{Andrew Marshall \\ Nat. Biotechnol. 30, 207 (2012); published online 7 March 2012; corrected after print 7 May 2012}

In the version of this article initially published, in the Table 'Transgenic crop and/or traits receiving approval', Syngenta was credited with product MON 87460-4. Monsanto owns MON 87460-4. The error has been corrected in the HTML and PDF versions of the article.

\section{Erratum: Around the world in a month}

Nat. Biotechnol. 29, 775 (2011); published online 8 September 2011; corrected after print 7 May 2012

In the version of this article initially published, the country of Peru, instead of Bolivia, was connected to the box on Bolivia. The error has been corrected in the HTML and PDF versions of the article.

\section{Erratum: Fate of novel painkiller mAbs hangs in balance}

Ken Garber

Nat. Biotechnol. 29, 173-174 (2011); published online 9 March 2011; corrected after print 7 May 2012

In the version of this article initially published, in Table 1 on p.174, Medi-578 was mistakenly said to be halted in phase 2 . In fact, it was stopped in phase 1. The error has been corrected in the HTML and PDF versions of the article. 